\title{
Percepção de risco e excesso de velocidade
}

\section{Risk perception and speeding}

\section{Abstract}

This paper discusses risk perception comparing drivers with and without fines for speeding. The research aimed to show the interaction between speeding laws and speeding behavior. Speeders' explanations for their behavior revealed important factors in the determination of risk perception: control (driver-centered), risk minimization (drivers claimed there was no risk involved in the way they speeded), self-confidence (they considered themselves good drivers and believed they were able to define what constitutes speeding), and lack of credibility in the institutions that manage traffic risks. Speeders display a cognitive construct of personal invulnerability combined with unrealistic optimism and overrated self-perception, along with an exaggerated perception of their control over the traffic setting, centered on their self-purported driving skills. No difference was found in risk perception between drivers in the two groups. There was no relationship between objective and perceived risks, since drivers from the two groups showed a generic perception of objective risks, but outof-context in relation to the inherent potential for accidents at different speeds.

Traffic Accidents; Risk-Taking; Motor Vehicles
Iara Picchioni Thielen 1

Ricardo Carlos Hartmann 1

Diogo Picchioni Soares 1

\section{Contextualização: ambiente urbano e trânsito}

As estatísticas apresentadas pela Comissão Mundial sobre Meio Ambiente e Desenvolvimento, em 1987 1, indicavam o crescimento acelerado das cidades, que deveriam aumentar a capacidade de produção de infra-estrutura, serviços e habitação, em torno de $65 \%$, nos países em desenvolvimento, num prazo de 15 anos. Atualmente, a qualidade de vida oferecida por uma cidade pode ser avaliada através de um dos aspectos mais significativos da vida urbana: o trânsito, que, com sua influência na vida e na morte do cidadão, relaciona-se diretamente com a saúde e se expressa por meio dos índices de morbi-mortalidade, os quais indicam que dois terços dos acidentes de trânsito acontecem em áreas urbanas 2.

O trânsito - definido como o conjunto dos deslocamentos realizados por pessoas e veículos nas vias públicas, segundo um sistema de normas convencionadas, que tem como objetivo assegurar a segurança dos usuários 3 - torna-se uma forma de controle demográfico ardilosa, constituindo-se na segunda maior causa de mortalidade no país (grupo das causas externas). "No Brasil o coeficiente de mortalidade por acidentes de trânsito, em 1994, era de 18,9 (por cem mil habitantes), sendo superior ao dos Estados Unidos (18,4), da França (16,5), da Argentina (9,1), entre outros" 2 (p. 9). Dados do Departamento Nacional de Trânsito, referentes a 2001, indicam um 
total de 9.704 mortes até junho, sendo que esses dados não incluem registros completos de alguns estados. "No Brasil, cerca de dois terços dos leitos hospitalares dos setores de ortopedia e traumatologia são ocupados por vítimas de acidentes de trânsito" (Pires et al., 1997, apud Marín \& Queiroz ${ }^{2}$, p. 8), revelando uma escala gigantesca de mutilações evitáveis.

Essas constatações transformam o trânsito em uma questão de Saúde Pública 2 e em um dos principais problemas dos ambientes urbanos. Estudos apontam para o excesso de velocidade como uma das maiores causas dos acidentes de trânsito e dos índices de morbi-mortalidade de pedestres 4 , ao lado da ingestão de álcool.

\section{Perspectiva de análise}

Este estudo aborda o excesso de velocidade no trânsito a partir do referencial da percepção dos riscos estudada pela Psicologia, mas destacar alguns marcos da teoria social sobre riscos é importante. Segundo Guivant 5 , é com Giddens 6 e Beck 7 que essa temática emerge no centro da teoria social. Para esses sociólogos, a sociedade industrializada enfrenta riscos ambientais e tecnológicos que são centrais e constitutivos dessa sociedade, promovendo ameaça constante e sendo fonte potencial de autodestruição. Portanto, a confiança nos peritos, na tecnologia, no progresso, na racionalidade do homem moderno e em sua capacidade de gerenciar as ameaças foi abalada. O medo, a desconfiança e a incerteza fazem parte do cotidiano na contemporaneidade. Os riscos são inerentes à modernidade. A análise da trajetória das análises de risco abordada por Guivant 5 indica a extensão, a multiplicidade de enfoques e a complexidade do tema. Embora reconhecendo a importância dos estudos sobre riscos na vertente sociológica e as contribuições pioneiras de Douglas 8 e Wildavsky ${ }^{9}$, não será esse o referencial privilegiado neste estudo para a análise do comportamento dos motoristas em relação ao excesso de velocidade.

Este estudo compartilha a idéia de que outras teorias podem ser úteis na compreensão do comportamento humano no trânsito 10,11, como é o caso da Teoria Geral dos de Sistemas 12, cujo alcance, já há muito, extrapola a vertente biológica na qual foi concebida. O trânsito pode ser analisado como um sistema composto por três subsistemas: a via, o veículo e o homem. São identificados diferentes níveis de complexidade 13, e alguns autores 12,14 salientam a existência de propriedades emergentes não acessíveis aos processos analíticos. Dessa forma, a Psicologia pode apropriar-se desse conjunto de pressupostos te- óricos permitindo construir um tipo de análise que incorpora os estudos sobre percepção de riscos como um dos insumos que influenciam o comportamento de dirigir.

Em relação aos riscos, duas vertentes de análise podem ser identificadas: de um lado, a avaliação de risco, desenvolvida pelas ciências naturais com utilização de instrumentos e modelos de determinação de riscos objetivos; de outro lado, a percepção de risco, estudada pelas ciências humanas 5,15,16,17,18,19.

A avaliação de riscos foi considerada uma atividade objetiva com enfoque predominantemente quantitativo, focalizando as causas dos fenômenos 16. As análises técnicas e quantitativas na temática dos riscos desconsideram que tanto causas como conseqüências dos danos são mediadas por experiências e interações sociais 20 . Nessa abordagem, o risco é definido: "como evento adverso, uma atividade, um atributo fisico, com determinadas probabilidades objetivas de provocar danos, e pode ser estimado através de cálculos de níveis de aceitabilidade que permitem estabelecer standards, através de diversos métodos (predições estatísticas, estimação probabilística do risco, comparações risco/benefício, análises psicométricas). O conceito de 'risco aceitável', decisivo nesta abordagem técnica, foi inicialmente formulado em 1969 por Starr" 5 (p. 3).

Uma outra vertente se contrapõe a essa suposta objetividade e compreende que a estimativa de riscos se dá num contexto de incertezas e ambigüidades. Constata-se a própria subjetividade dos peritos, já que diferentes sistemas e referenciais são utilizados para avaliar riscos e, portanto, há divergências no que se refere a métodos de estimativa de riscos, de determinação de níveis de tolerância e aceitação de riscos, além da comunicação e administração de riscos. Isso corrói a idéia de objetividade, enfatizando a necessidade de se incluir outros níveis de análise 15, já que a percepção dos leigos foi vista em oposição à avaliação de riscos feita pelos técnicos, e que ambas estão permeadas de pressupostos morais e sociais advindos das experiências de cada um e que respondem a racionalidades diferentes 21

Embora a perspectiva cognitiva (conhecimento e controle) esteja presente no conceito de risco percebido, Lima 16 (p. 16) destaca “os esforços individuais de gestão da ameaça, que levam freqüentemente a estratégias de minimização do risco" e afirma que "a percepção de riscos tem muito mais a ver com medo do que com uma estimativa correta de probabilidades". A percepção dos leigos estudada pela Psicologia cognitiva teve grande influência a partir dos estudos conduzidos por Fischhoff et al. 22 . 
Teorias específicas da Psicologia enfatizam o comportamento humano no trânsito considerando a motivação como elemento chave, como a Teoria do Risco Zero 23 e a Teoria da Homeostase do Risco ${ }^{24}$. A Teoria do Risco Zero postula que a percepção do risco (de acidente ou de sanção) é igual a zero na maior parte do tempo (risco subjetivo nulo), e que os acidentes seriam motivados pela diferença entre o risco objetivo (real) e o subjetivo. O modelo proposto por Wilde 24 indica que as pessoas aceitam um certo grau de risco subjetivamente estimado para sua saúde e segurança que deriva de três fontes: as experiências passadas, a estimativa do potencial de acidente da situação e o grau de confiança na habilidade de tomar decisões e controlar o veículo para enfrentar a situação. Em ambas as teorias, o conceito de risco percebido assume um papel central.

Por percepção de risco entende-se a forma como os leigos pensam sobre o risco e inclui um conjunto de crenças e valores que dão significado a um acontecimento ameaçador 16,17. Ao considerar o comportamento como um sistema, é possível classificar fatores externos (do meio ambiente) e internos (do próprio indivíduo) que contribuem para a organização das percepções frente aos riscos e que orientarão o comportamento de prevenção de acidentes.

A Teoria Geral dos Sistemas 12 permite a análise do comportamento humano no trânsito como um sistema que resulta em excesso de velocidade, bem como auxilia na identificação de fatores que influenciam o comportamento do motorista. A Figura 1 ilustra alguns dos insumos do sistema que são processados para que a decisão final resulte em comportamentos de risco ou comportamentos seguros. Entre os insumos, destaca-se a percepção de riscos.

Embora os insumos arrolados detalhem fatores internos e externos, é importante enfatizar que não se trata de fatores isolados, mas em interação. Da mesma forma, o processo representado destaca algumas ações encadeadas que fundamentam a tomada de decisão: detecção das variáveis envolvidas - sejam estímulos do ambiente, sejam informações, como aquelas decorrentes da legislação; decodificação dos dados com base em variáveis individuais, grupais, culturais ou ideológicas; seleção de estímulos aos quais vai responder ou ignorar; análise das variáveis envolvidas seja em relação às conseqüências das opções de ação, seja em relação ao jogo de forças presente na situação; compreensão das variáveis, dos estímulos e da relação entre eles no contexto; significado atribuído a cada um dos elementos presentes na situação e à interação entre eles. Após as ponderações sobre todo esse

jogo de interações a partir de variáveis cognitivas, afetivas e dos possíveis resultados das ações que podem ser empreendidas, o indivíduo opta por tomar a decisão que resulta em determinado curso de ação. No caso em estudo, sintetiza-se o produto do comportamento em exceder ou não a velocidade.

A percepção de riscos envolvidos no trânsito é um fator importante que é mediado pelo contexto, e os acidentes de trânsito decorrem dos riscos que o ser humano aceita 25 , e a aceitação de riscos aumenta na mesma proporção em que aumenta a implementação de dispositivos de segurança 24 . Na relação do indivíduo em trânsito, os riscos são permanentes. A Figura 1 indica que os riscos precisam ser detectados, decodificados, além de significativos, para que o indivíduo tome decisões no trânsito compatíveis com a situação de risco em questão. Se o risco não é percebido como tal, as decisões e comportamentos não serão compatíveis com a segurança que a situação exige. "As pessoas reagem aos riscos que percebem. E se suas percepções forem equivocadas, esforços de proteção nos âmbitos pessoal, público e ambiental podem ser mal orientados" 18 (p. 463 - tradução do autor).

Silcock et al. 26 indicam que $85 \%$ dos motoristas excedem os limites de velocidade ocasionalmente, embora percebam o excesso de velocidade como uma infração; além disso, o limite de velocidade percebido subjetivamente está acima

Figura 1

Ilustração de um sistema de comportamento que resulta em excesso de velocidade.

INSUMOS

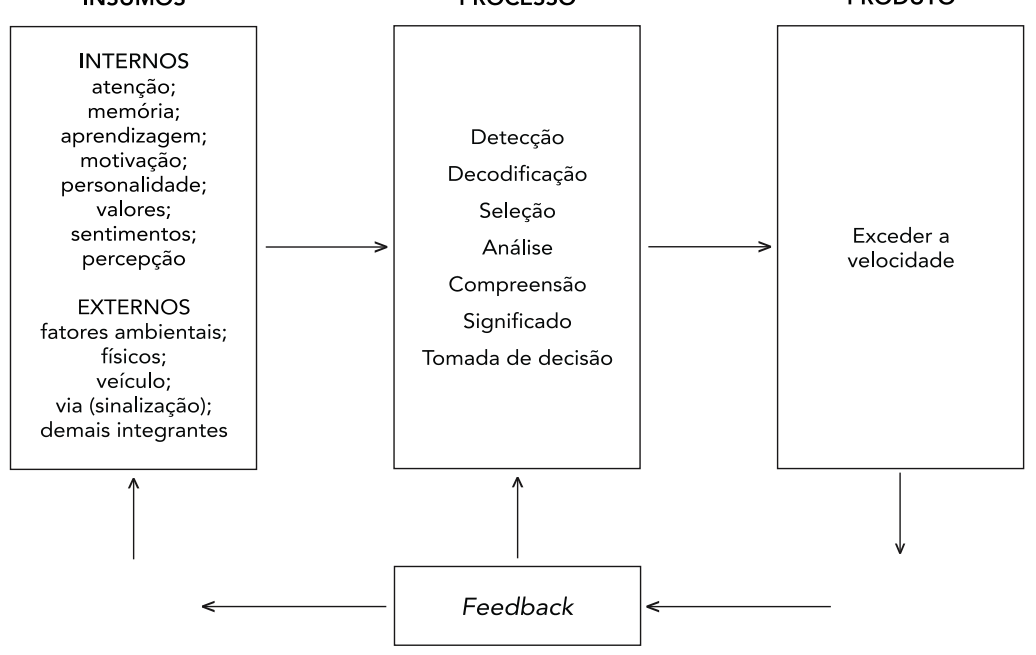


do estabelecido pela norma, e os motoristas argumentam que exceder moderadamente o limite de velocidade não representa perigo. A ausência de razão aparente para a determinação de limites de velocidade é um fator que leva à infração 26 .

\section{Objetivo e procedimentos}

Este artigo identifica e analisa os fatores envolvidos na percepção de risco dos motoristas em relação ao excesso de velocidade.

\section{Participantes}

Foram entrevistados 20 motoristas com mais de nove multas por excesso de velocidade e 16 motoristas sem multas, da cidade de Curitiba, Paraná, Brasil. O primeiro contato foi telefônico, com a apresentação da pesquisadora, dos objetivos e da forma de obtenção dos dados pessoais sobre as multas, quando então era solicitada a informação sobre a autoria das infrações, condição para integrar o grupo de multados a ser pesquisado. Foi solicitado o consentimento para participação na pesquisa, bem como foi assumido o compromisso de sigilo de todas as informações que pudessem identificar os participantes. As entrevistas foram realizadas na residência ou local de trabalho dos participantes, conforme sua escolha. Para os motoristas não multados, o procedimento foi semelhante.

Os motoristas multados entrevistados foram identificados por sexo e idade, e as mesmas variáveis foram consideradas para selecionar e entrevistar motoristas sem infrações, significando que essa amostra foi dirigida a partir de listagem específica emitida pelo DETRAN-PR (Departamento de Trânsito do Paraná). No entanto, a coleta de dados restringiu-se a 16 motoristas, em função da impossibilidade de manter contato ou de se efetivar as entrevistas.

Composição da amostra: para localizar os motoristas infratores, foi analisada uma listagem fornecida pelo DETRAN-PR, emitida em 29 de janeiro de 2001, que identifica 441 motoristas com nove ou mais multas por excesso de velocidade. No entanto, ainda não era possível afirmar que esses motoristas multados fossem os responsáveis pelas infrações. Desse total de 441 motoristas, foram excluídos 406 [sem possibilidade de localização (217), telefone incorreto ou desligado (54), várias tentativas de contato (80), recado sem retorno (14), participaram de reciclagem (10), declararam-se não autores das infrações (30), não quis participar (1)], e 35 motoristas declararamse autores das infrações, sendo que, com 15 deles, não foi possível realizar as entrevistas. Enfim, da listagem contendo 441 motoristas, foi possível localizar, fazer as triagens e entrevistar 20 deles.

Caracterização dos motoristas: são 20 motoristas multados, sendo 3 mulheres e 17 homens, todos com idade acima de 30 anos; 11 com curso superior, 8 com o ensino médio e 1 completou o ensino fundamental. Dos 16 motoristas não multados: 2 com mestrado, 6 com curso superior, 3 com o curso médio, 3 com o ensino fundamental e 2 não completaram o ensino fundamental. A maioria dos motoristas dirige a maior parte do tempo só, em ambos os grupos.

O roteiro de entrevista continha 25 questões abordando: conceituação de excesso de velocidade, significado, riscos, sentimentos, fatores responsáveis pelo comportamento de exceder a velocidade, impacto das multas em relação à prevenção (somente para multados), mudança de comportamento (idem), fiscalização eletrônica, conhecimento de distâncias de frenagem e percepção do comportamento do outro grupo pesquisado.

A análise qualitativa indicou as convergências e divergências entre os dois grupos de entrevistados, com base nos fatores que afetam a percepção de risco, tais como: controle; confiança; consciência do risco; confronto entre risco objetivo e risco percebido; grau de familiaridade com o risco; gravidade do risco; extensão dos danos; e responsabilidade pela prevenção 15,16,27,28,29,30. A partir das respostas dos motoristas, foi possível construir agrupamentos que se consolidaram em categorias, cuja base se encontra nos fatores que afetam a percepção de riscos.

\section{Análise dos depoimentos}

Para ilustrar a análise, alguns depoimentos foram transcritos em itálico, com indicação de multado (M) ou não multado $(\mathrm{N})$.

Quando os motoristas responderam "o que é excesso de velocidade?", permitiram identificar três categorias de respostas: (1) definições que fazem referência à via; (2) definições que fazem referência à lei ou à via, mas apresentam distorções pessoais; e (3) definições pessoais.

A primeira categoria inclui definições de excesso de velocidade que fazem referência à via como determinante do limite de velocidade. É exemplo a seguinte resposta: "Existe um ideal de velocidade para cada lugar, cada região, em função da estrutura. As velocidades estão fixadas adequadamente. Existem normas técnicas que estabelecem isso. Acho-me incapaz de julgar se as ruas estão com velocidades adequadas ou não" (M).

A segunda categoria inclui definições de excesso de velocidade que fazem referência à lei ou 
à via, mas apresentam ambivalências demonstrando uma visão particularizada que distorce o que a lei prevê. Ou seja, sempre há uma ponderação que perverte o sentido expresso em lei e que particulariza o excesso. Na percepção desses motoristas, a velocidade na qual eles transitam não deve ser considerada como excesso. Essa distorção a partir de uma análise estritamente pessoal confirma a idéia de reinterpretação do conhecimento perito pelos leigos, ou seja, os motoristas levam em consideração o fator indicado na própria lei (tipo de via), porém com características pessoais. Para compreender alguns depoimentos, é importante registrar que, em Curitiba, a população denomina incorretamente de "via rápida" algumas vias, e nelas a velocidade máxima determinada pelos órgãos oficiais é de $60 \mathrm{~km} / \mathrm{h}$.

"Acho que depende das vias. Numa via rápida, excesso é acima de 80" (M). "Ultrapassar os limites, conforme a sinalização. Eu estava a 62, 70, quando fui multado. Qual a diferença entre 60 e 70 ? É muito pouco. Antigamente era 80 na estrada, hoje é 110. Isto prova que nem sempre a sinalização está correta" (M). "Ultrapassar os limites de cada um. Cada um define. Mas tem que ter as normas. [E após reflexão.] Ultrapassar os limites estabelecidos pelo código/órgão competente. As minhas multas são entre 67, 69, 72 e 75, nada de 80, 90, 100" (M). "É a velocidade incompativel com o local. Andar a 70/80 na via rápida não é excesso" (M). "É andar acima da placa. Se está livre, pode passar, sem abusar muito" (N). "Se é na cidade, se está acima de 100 já é um excessozinho. Na estrada nunca ando mais de 120. Até 80 não é excesso. Se bem que depende onde está, depende das placas. Depende da velocidade permitida. Procuro obedecer o que o local permite" (N). "Isto é muito relativo. Legal é infringir, exceder o que é previsto para cada via. Mas entendo também que tem a ver com a condição do veículo. Se as pessoas tivessem noção dos tipos de vias controlariam melhor essas informações" (N).

A terceira categoria, a mais preponderante, inclui definições de excesso de velocidade com caráter pessoal, que contrariam o texto da lei. Essas definições propiciam a identificação dos fatores internos que são levados em conta pelo motorista quando ele adota uma determinada velocidade. Dentre esses fatores, destacam-se o controle e a confiança, alocados principalmente no próprio motorista ou mesmo no carro, como relevantes na definição do que é excesso de velocidade. Os depoimentos, a seguir, ilustram essa terceira categoria.

"É ultrapassar o limite em local onde não há possibilidade do uso do veículo no seu potencial. Não é dito por uma placa. É um momento e um local. A placa é só um referencial" (M). "Velocidade superior à velocidade necessária para ter pleno controle do veículo" (M). "É transitar numa velocidade não compatível com as condições de segurança da pista. Com carros em bom estado, o limite deve ser pelo menos de 80/90, nas vias rápidas. O ideal seria deixar por conta do motorista (a definição de excesso)" (M). "Dirigir o veículo de uma forma que não tenha controle. Tem que ter bom senso, além das velocidades liberadas, tem que sentir" (M). "Não ter controle numa emergência em desviar ou parar o veículo" (M). "Conceitos de velocidade mudam tanto com o tempo. Não me senti multado por excesso de velocidade" (M). "Ultrapassar o limite seu, do carro. Não é necessariamente a velocidade da placa. Concepção de alta velocidade tem várias" (M). "É aquela que foge do controle, de domínio do veículo. Na chuva pode ser 60, 70. Numa estrada ir a 120, 130, num belo dum carro não é excesso" (M). "Além do que a pessoa sente seguro dirigir. Não é só o radar” (N).

"Não conseguir mais controlar o veículo. $\mathrm{Na}$ periferia 80 já não é tanto" (N). "Mais de 70, 80 na cidade" (N). "É estar acima da velocidade da maioria dos carros. O meio ambiente dita a regra de como tem que agir" $(\mathrm{N})$. "Exceder o limite seguro de trânsito numa via” (N).

É importante destacar, em cada uma dessas definições de excesso de velocidade, as variáveis presentes: a sinalização, o controle alocado no próprio motorista, o controle exercido sobre o motorista e a confiança.

Os motoristas infratores pesquisados ignoram a indicação das placas de sinalização de velocidade por diversas razões. Uma delas é a falta de credibilidadedasinstâncias responsáveispeladeterminação da velocidade máxima permitida 26 , bem como o desconhecimento dos parâmetros que norteiam essa determinação, expressa por um motorista ao afirmar que "antigamente era 80 na estrada, hoje é 110, isto prova que nem sempre a sinalização está correta" (M). Isso atesta que a confiança nos órgãos que devem definir as velocidades foi abalada, e, em decorrência, a percepção dos riscos fica comprometida por esse descrédito fazendo com que o motorista se balize por critérios internos, pessoais, sem levar em conta parâmetros técnicos ou legais como norteadores de seu comportamento.

Um motorista infrator afirmou que "menos de 60 não é excesso no perímetro urbano" (M). Na percepção desse motorista, há uma confiança no limite de velocidade de $60 \mathrm{~km} / \mathrm{h}$ no perímetro urbano que imprime certas garantias ou imuniza contra riscos. Nesse caso, identificam-se o controle, a minimização do risco, a confiança e a baixa credibilidade nas instâncias que devem gerenciar as ameaças 16 como alguns dos fatores 
que determinaram a percepção de risco desse motorista.

Outro fator identificado refere-se à crença dos motoristas infratores em poder estabelecer os limites de velocidade aceitáveis, partindo de parâmetros diversos daqueles preconizados tecnicamente e, quase sempre, auto-referenciados ("não me sinto multado por excesso de velocida$d e$ "). Quando o motorista afirma que excesso de velocidade é "dirigir de uma forma que não tenha controle”, identifica-se que é ele próprio o balizador desse limite. Também, dispensa-se qualquer determinação externa, além do equívoco de que se ele tiver controle não há risco.

Entretanto, segundo os motoristas infratores, a responsabilidade pelo cometimento da infração nunca é deles próprios: ou o equipamento não está aferido ("acho que a medição não está correta, ou meu velocímetro não está correto”), ou o equipamento foi colocado propositadamente para multar, ou a velocidade fixada não é adequada, ou a pista não é adequada, ou a sincronização dos semáforos induz a uma velocidade acima daquela permitida ("para pegar todos os semáforos abertos, eu preciso ir numa velocidade um pouco acima de 60"). Ou seja, desloca-se a responsabilidade para fatores externos, de modo que o motorista deixa de perceber que só ele é capaz de executar os movimentos básicos dentro do veículo - acelerar ou frear -, determinando a velocidade na qual o veículo vai se deslocar. Alguns motoristas alegaram que o radar foi colocado "justamente numa descida", e, portanto, para "pegar o motorista", sugerindo que não é o motorista que define a velocidade do veículo, mas a força da gravidade; ou, ainda, alegaram que a topografia da via determinou a velocidade: "é uma baixada ali, automaticamente já está a mais de 60 ". Esse deslocamento de responsabilidade pela infração para fatores externos se contrapõe à alocação interna de controle pela determinação da velocidade máxima permitida.

Ao confrontar as idéias de "suposto" controle por parte dos motoristas infratores, verifica-se que eles não têm noções fundamentais de processos de frenagem e a influência do tempo de reação nesses processos. Ainda que os reflexos sejam mantidos, velocidades diferentes significam riscos potenciais diferentes. Nesse caso, a percepção do risco está distorcida pelo desconhecimento de aspectos técnicos do processo de frenagem, associado à autopercepção do "equilíbrio psicológico", da "boa coordenação motora” e do "não envolvimento em acidentes", como justificativas para a minimização e controle dos riscos envolvidos em exceder a velocidade. É como se esses fatores imunizassem o motorista em relação aos riscos do excesso de velocidade.

\section{Motoristas multados e não multados}

Os motoristas que fazem referência à lei e à sinalização como os balizadores do excesso de velocidade são poucos. As definições pessoais ou as distorções pessoais em relação à lei predominam no discurso dos motoristas, infratores ou não. Ou seja, não importa se um motorista foi ou não multado, a percepção que ele tem do parâmetro que norteia o excesso de velocidade é a mesma: o centro do qual emanam as regulamentações é ele próprio, significando que a velocidade no trânsito se converte num fenômeno individual para o qual a maioria tem uma receita própria. Somente dois motoristas (um de cada grupo) referiram-se à lei como parâmetro regulador da velocidade permitida.

As pesquisas de Lima 15,16 indicam que ao maior risco objetivo corresponde uma maior consciência da ameaça, mas, em contrapartida, há uma percepção de que esse risco é mais controlável (risco subjetivo). No caso do trânsito, a proximidade e convivência diárias com os riscos provocam uma negação, na medida em que os riscos são identificados, mas se referem a velocidades diferentes daquela na qual o motorista transita. A negação do risco pode ser caracterizada como uma estratégia defensiva, pois níveis elevados de ameaça engendram estratégias cognitivas de minimização do risco 16 . Embora, no trânsito, a ameaça seja constante, não há uma correspondência entre riscos objetivos e riscos percebidos, já que os motoristas percebem os riscos de maneira genérica, descontextualizados do risco potencial embutido em diferentes velocidades. A partir da percepção distorcida do motorista acerca do seu controle, de sua perícia e habilidade, não é a "sua" velocidade que oferece riscos.

Ao associarem os riscos decorrentes do excesso de velocidade a velocidades diferentes daquelas estabelecidas pela legislação, os motoristas infratores revelam construções cognitivas de invulnerabilidade pessoal relacionada a um otimismo irrealista de que não há riscos, associadas a uma autopercepção superavaliada de que o problema são os outros e também uma exagerada percepção de controle sobre o ambiente 15,28,29,31.

A Figura 2 destaca o papel da fiscalização eletrônica no processo de tomada de decisão que resulta em "ser ou não multado". A Figura 2 sintetiza a intermediação feita pela fiscalização eletrônica que passa a exercer um papel importante no processamento das informações e na tomada de decisão, ou seja, não é o insumo "placa com limite de velocidade" que orienta o comportamento do motorista, mas a existência ou não da 
fiscalização eletrônica. O insumo "placa com limite de velocidade" se desloca para "presença de fiscalização eletrônica”. E é a aceitação ou rejeição da fiscalização que atuam no processo decisório, resultando em comportamento de ser ou não multado. Porque exceder a velocidade todos eles admitiram, explícita ou veladamente.

\section{Considerações finais}

Os motoristas de ambos os grupos pretendem reinterpretar a lei, identificando velocidades máximas diferentes daquelas definidas na legislação, cujos parâmetros estão acima dos limites legais estabelecidos 32 . Não há diferença de percepção de riscos do excesso de velocidade para motoristas infratores e não multados.

As definições pessoais predominam no discurso dos motoristas, infratores ou não. A perspectiva a partir da qual avaliam as regulamentações é a do próprio motorista, indicando que o trânsito, um fenômeno público por excelência, transforma-se num fenômeno individual, pessoal, privado. Os parâmetros individuais são sustentados pela percepção de que o controle da atividade de dirigir está centralizado na perícia do motorista e não numa articulação entre os diversos fatores envolvidos e regulados pela legislação que organiza a convivência harmônica dos integrantes do trânsito.

Os motoristas infratores, além de definirem parâmetros próprios de excesso de velocidade, pretendem definir quem, onde e que instrumento é ou não adequado para mensurar a infração. As informações incorretas sobre processos de frenagem confirmam que, embora os motoristas pretendam estabelecer as regras para a determinação de velocidades máximas permitidas, desconhecem mecanismos básicos para suas definições.

Quando os motoristas de ambos os grupos identificam os riscos decorrentes do excesso de velocidade, focalizam os mesmos riscos genéricos presentes no trânsito sempre que uma infração ou um acidente ocorrem, tais como: danos materiais, financeiros e humanos, que podem ocasionar desde conseqüências leves até morte. Entretanto, os motoristas deslocam os riscos do contexto no qual foram identificados e que serviu de base para sua inclusão no contexto legal (velocidade máxima permitida em lei) e fazem associação com velocidades diferentes. Portanto, não se trata dos mesmos riscos. O risco de atropelamento ou morte no trânsito é diferente em diferentes velocidades. Essa reinterpretação da lei, identificando velocidades máximas diferentes, patenteia a desconfiança dos motoristas
Figura 2

Ilustração da influência da fiscalização no processo de tomada de decisão.

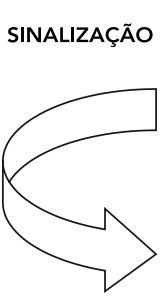

FISCALIZAÇÃO

SER OU NÃO

MULTADO

INSUMO
Aceitação

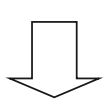

PROCESSAMENTO

DECISÃO

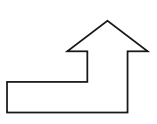

PRODUTO

nas instituições responsáveis pela definição dos

limites de velocidade.

Os motoristas infratores, ao se colocarem como sujeitos da infração, indicam diversos mecanismos para analisar a sinalização e a fiscalização, que são contraditórios e que revelam tanto uma negação do seu comportamento de risco e a desqualificação da fiscalização quanto a insistência na responsabilidade de instâncias externas para prover uma fiscalização mais adequada. Ao mesmo tempo em que negam sua responsabilidade, vêem-se obrigados a sucumbir à evidência das multas aplicadas. Ao mesmo tempo em que individualizam o controle da atividade de dirigir e de definir o que é excesso de velocidade, os motoristas deslocam esse controle para elementos externos quando se trata de otimizar o comportamento no trânsito.

Os motoristas não multados foram questionados quanto a exceder ou não a velocidade máxima permitida e quanto à fiscalização eletrônica. Os motoristas são ambíguos, pois admitem que excedem a velocidade ocasionalmente, mas, ao mesmo tempo, manifestam uma concordância com a fiscalização eletrônica, alguns deles chegando a sugerir que ela deve ser ainda mais intensiva. O grupo de motoristas não multados indica motivos de aceitação dos limites e da fiscalização imposta.

Essa diferença atribuída pelos motoristas ao papel da fiscalização eletrônica, bem como as diferenças de hetero-percepção salientadas pelos motoristas não multados sugerem que a aceitação da fiscalização e a atribuição de um significado que se volta para o interesse público podem ser mecanismos significativos que resultam em comportamentos diferentes. Ao perceber o mecanismo de fiscalização como uma decor- 
rência do sentido público expresso no trânsito e não como contestação a liberdades individuais, é possível adotar comportamentos compatíveis com as normas.

A partir deste estudo, constata-se que o papel da fiscalização eletrônica como instrumento para coibir o excesso de velocidade se mostrou útil: (a) nas percepções dos motoristas infratores, por imposição; (b) nas percepções dos motoristas não multados, por aceitação de um mecanismo regulador que orienta o trânsito; (c) na análise técnica dos órgãos responsáveis pelo gerenciamento da fiscalização, pela constatação da redução de acidentes e da velocidade.

Dessa forma, o insumo "placas de sinalização e de excesso de velocidade" é mediado pela fiscalização. E sua aceitação ou rejeição modifica o processamento das informações, resultando em comportamentos "ser ou não

\section{Resumo}

Este trabalho discute percepção de riscos no trânsito, comparando um grupo de motoristas infratores a um grupo de motoristas sem multas por excesso de velocidade. O objetivo da pesquisa foi explicitar a interação entre a norma de velocidade e o comportamento de excesso de velocidade. Nas justificativas para o excesso de velocidade, foram identificados importantes fatores na determinação da percepção de risco: controle (centralizado no motorista), minimização do risco (a velocidade na qual eles transitam não oferece riscos), confiança (eles se julgam hábeis motoristas e podem definir o que é excesso de velocidade) e falta de credibilidade nas instâncias que devem gerenciar as ameaças. Os infratores revelam uma construção cognitiva de invulnerabilidade pessoal, associada a um otimismo irrealista e autopercepção superavaliada, aliadas a uma exagerada percepção de controle sobre o ambiente, centralizado em sua perícia e habilidade. Não há diferença de percepção de riscos entre os motoristas dos dois grupos. Não há correspondência entre riscos objetivos e riscos percebidos, pois os motoristas dos dois grupos percebem riscos objetivos genericamente considerados, porém descontextualizados da potencialidade para acidentes embutida em diferentes velocidades.

Acidentes de Trânsito; Assunção de Riscos; Veículos Automotores multado". A fiscalização faz a mediação entre a norma e o comportamento, na medida em que sua presença sinaliza a potencialidade de riscos e o benefício público advindo da submissão a ela. A partir dos depoimentos dos motoristas infratores, essa mediação foi identificada através da preocupação voltada para a presença dos mecanismos de fiscalização eletrônica da velocidade e não para a velocidade, indicando que o estímulo discriminativo para obediência à norma se deslocou da sinalização para a fiscalização.

Em suma, este estudo sobre o excesso de velocidade evidencia a percepção individualista de um fenômeno que é coletivo (trânsito), analisando alguns fatores que contribuem para essa distorção de percepção dos riscos identificada tanto entre motoristas infratores como entre motoristas sem multas.

\section{Colaboradores}

I. P. Thielen desenvolveu a pesquisa e elaborou o manuscrito. R. C. Hartmann participou da criação, redação e revisão final do texto para publicação. D. P. Soares participou das etapas de seleção de conteúdos e criação do texto, além da redação de explicações complementares às Figuras 1 e 2 e conteúdos específicos da Teoria Geral dos Sistemas.

\section{Agredecimentos}

A Coodenação de Aperfeiçoamento de Pessoal de Nível Superior (CAPES) pelo financiamento da pesquisa. 


\section{Referências}

1. Comissão Mundial sobre Meio Ambiente e Desenvolvimento. Nosso futuro comum. Rio de Janeiro: Fundação Getúlio Vargas; 1991.

2. Marín L, Queiroz MS. A atualidade dos acidentes de trânsito na era da velocidade: uma visão geral. Cad Saúde Pública 2000; 16:7-21

3. Rozestraten RJA. Psicologia do trânsito: conceito e processos básicos. São Paulo: E.P.U.; 1988.

4. Almeida IS, Freitas MF. Acidente de trânsito com vítimas em Brasília (DF) e sua relação com a velocidade dos veículos envolvidos. Brasília Médica 1995; 32:21-9.

5. Guivant JS. A trajetória das análises de risco: da periferia ao centro da teoria social. Revista Brasileira de Informação Bibliográfica em Ciências Sociais 1998; (46):3-38.

6. Giddens A. As conseqüências da modernidade. São Paulo: Editora da Universidade Estadual Paulista; 1991.

7. Beck U. Risk society: towards a new modernity. London: Sage Publications; 1992.

8. Douglas M. Purity and danger: an analysis of conceptions of pollution and taboo. London: Routledge; 1966.

9. Douglas M, Wildavsky A. Risk and culture. An essay on selection of technical and environmental dangers. Berkeley: University of California Press; 1982.

10. Fuller R. The psychology of theories and a theory of psychology. In: Rothengatter T, Carbonell E, editors. Traffic and transport psychology: theory and application. Amsterdam: Pergamon; 1997. p. 53-8.

11. Grayson GB. Theories and models in traffic psychology: a contrary view. In: Rothengatter T, Carbonell E, editors. Traffic and transport psychology: theory and application. Amsterdam: Pergamon; 1997; p. 93-6.

12. Von Bertalanffy L. Teoria geral dos sistemas. Petrópolis: Editora Vozes; 1973.

13. Ávila-Pires FD. Medical ecology, holism and circular reasoning in medicine. In: Susanne C, Gallé L, editors. Ecotechnie and sustainable development. Szeged: Officina Nyomda; 1998. p. 205-18.

14. Bergandi D. Fundamentals of ecology de E. P. Odum: véritable "approche holiste" ou reductionnisme masqué? Bulletin d' Écologie 1992; 24:57-68.

15. Lima ML. Viver com o risco: abordagens da psicologia social ambiental. Inforgeo 1995; 9-10:39-54.
16. Lima ML. Factores sociais na percepção de riscos. Revista da Associação Portuguesa de Psicologia 1998; 12:11-28.

17. Pidgeon N, Hood C, Jones D, Turner B, Gibson R. Risk perception. In: Royal Society Study Group, editor. Risk: analysis, perception and management. London: The Royal Society; 1992. p. 89-134.

18. Slovic P, Fischhoff B, Lichtenstein S. Facts versus fears: understanding perceived risk. In: Kahneman D, Slovic P, Tversky A, editors. Judgment under uncertainly: heuristics and biases. Cambridge: Cambridge University Press; 1982. p. 463-89.

19. Slovic P. Perception of risk. Science 1987; 236: 280-5.

20. Renn O. Concepts of risk: a classification. In: Krimsky S, Golding D, editors. Social theories of risk. London: Praeger; 1992. p. 53-79.

21. Wynne B. Risk and social learning: reification to engagement. In: Krimsky S, Golding D, editors. Social theories of risk. London: Praeger; 1992. p. 275300.

22. Fischhoff B, Lichtenstein S, Slovic P, Derby S, Keeny R. Acceptable risk. Cambridge: Cambridge University Press; 1981.

23. Näätäänen R, Summala H. A model for the role of motivational factors in drivers' decision-making. Accid Anal Prev 1974; 6:243-61.

24. Wilde GJS. Target risk. Ontario: PDE Publications/ Castor \& Columba; 1994.

25. Dotta A. Condutor defensivo. Porto Alegre: Sagra Luzzatto; 1973.

26. Silcock D, Smith K, Knox D, Beuret K. What limits speed? Factors that affect how fast we drive. s.l.: AA Foundation for Road Safety Research; 1999.

27. Kates RW, Burton I, White GF. The environment as hazard. New York: Oxford University Press; 1978.

28. Langer EJ. The illusion of control. J Pers Soc Psychol 1975; 32:311-28.

29. Weinstein ND. Unrealistic optimism about future life events. J Pers Soc Psychol 1981; 39:806-20.

30. White GF. Natural hazards: local, national, global. New York: Oxford University Press; 1974.

31 Taylor SE, Brown J. Illusion and well being: a social psychological perspective on mental health. Psychol Bull 1988; 103:193-210.

32 Thielen IP. Percepção de motoristas sobre excesso de velocidade no trânsito de Curitiba, Paraná, Brasil [Tese de Doutorado]. Santa Catarina: Universidade Federal de Santa Catarina; 2002.

Recebido em 10/Nov/2006

Versão final reapresentada em 24/Mai/2007

Aprovado em 05/Jun/2007 